\title{
THE FEDERAL AVIATION ADMINISTRATION 2008 PORTFOLIO FOR RESEARCH AND DEVELOPMENT
}

\author{
Paul Krois, Lee Olson, and Cathy Bigelow \\ Federal Aviation Administration, Washington, DC
}

\begin{abstract}
The Federal Aviation Administration (FAA) 2008 National Aviation Research Plan (NARP) is a performance-based plan that integrates and describes the FAA research and development (R\&D) portfolio. The 2008 NARP supports both the current day-to-day operations of the National Airspace System (NAS) and the future vision for the Next Generation Air Transportation System (NextGen). The portfolio is comprised of $44 \mathrm{R} \& \mathrm{D}$ programs that address air traffic management (ATM), aircraft safety, airports, the environment, human factors, operational concepts, aviation weather, unmanned aircraft, and wake turbulence requirements. In the $2008 N A R P$, ten R\&D goals bridge the near-term goals of the FAA's strategic Flight Plan, the mid- and longer-term NextGen goals of the Operational Evolution Partnership (OEP), now called the NextGen Implementation Plan, and the work of the Joint Planning and Development Office. This integrated approach enables the FAA to address the current challenges of operating the safest, most efficient air transportation system in the world while building the research foundation for NextGen.
\end{abstract}

\section{Introduction}

The Federal Aviation Administration (FAA) 2008 National Aviation Research Plan (NARP) is a performance-based plan that integrates and describes the FAA research and development (R\&D) portfolio. The 2008 NARP supports both the current day-to-day operations of the National Airspace System (NAS) and the future vision for the Next Generation Air Transportation System (NextGen) [1]. The portfolio is comprised of 44 R\&D programs that address air traffic management (ATM), aircraft safety, airports, the environment, human factors, operational concepts, aviation weather, unmanned aircraft, and wake turbulence requirements. In the $2008 N A R P$, ten R\&D goals bridge the near-term goals of the FAA's strategic
Flight Plan, the mid- and longer-term NextGen goals of the Operational Evolution Partnership (OEP), now called the NextGen Implementation Plan [2], and the work of the Joint Planning and Development Office. This integrated approach enables the FAA to address the current challenges of operating the safest, most efficient air transportation system in the world while building the research foundation for NextGen.

Title 49 of the U.S. Code section 44501(c) requires the FAA Administrator to submit the NARP to Congress annually with the President's Budget. In fiscal year 2009 the FAA plans to invest a total of $\$ 336,629,000$ in R\&D. This investment is drawn from four FAA appropriations accounts and includes: $\$ 171,028,000$ in Research, Engineering and Development; $\$ 131,128,000$ in Air Traffic Organization (ATO) Capital; $\$ 34,348,000$ in the Airport Improvement Program; and \$125,000 in Safety and Operations.

One of the major initiatives intended to reduce delays and congestion in our nation's air transportation system is the development of NextGen. This innovative vision includes three performance targets for the year 2025 that, if achieved, will provide three-times the capacity of our current system, at higher efficiency levels than we have today, to greatly reduce congestion. The FAA has integrated NextGen into its planning activities, including its five-year strategic Flight Plan [3]. The NextGen Implementation Plan provides the complete path of all FAA NextGenrelated activities, including contributions from research.

The Joint Planning and Development Office (JPDO) was created to ensure that the future operational environment is safe, well managed, environmentally responsible, and harmonized with international standards. In keeping with its charter, this inter-agency office has responsibility for defining and facilitating the implementation of NextGen [4]. 


\section{R\&D Goals}

The ten R\&D goals that integrate the program content of the 2008 NARP are:

- Fast, Flexible and Efficient - a system that safely and quickly moves anyone and anything, anywhere, anytime on schedules that meet customer needs

- Clean and Quiet - a reduction of significant aerospace environmental impacts in absolute terms

- High Quality Teams and Individuals the best qualified and trained workforce in the world

- Human-Centered Design - aerospace systems that adapt to, compensate for, and augment the performance of the human

- Human Protection - a reduction in fatalities, injuries, or adverse health impacts due to aerospace operations

- Safe Aerospace Vehicles - a reduction in accidents and incidents due to aerospace vehicle design, structure, and subsystems

- Self-Separation - a reduction in accidents and incidents due to aerospace vehicle operations in the air and on the ground

- Situational Awareness - common, accurate, and real-time information on aerospace operations, events, crises, obstacles, and weather

- System Knowledge - a thorough understanding of how the aerospace system operates, the impact of change on system performance and risk, and how the system impacts the nation

- World Leadership - a globally recognized leader in aerospace technology, systems, and operations

The R\&D goals of Human Protection and Safe Aerospace Vehicles address near-term safety needs associated with aviation standards, certification and other regulatory matters. The R\&D goal of SelfSeparation is uniquely designed to research key NextGen policy and standards that will lead to the technologies, procedures and training needed to delegate greater separation responsibilities to the flight deck.

The relationships between the FAA Flight Plan goals, R\&D goals, NextGen guiding principles, and JPDO Integrated Plan goals are shown in Table 1.

\section{R\&D by Lines by Business}

Five FAA Lines of Business (LOBs) are responsible for defining the agency's R\&D needs and requirements. These LOBs, and the number of R\&D programs associated with each, consist of the following:

- Air Traffic Organization (ATO) - 19 programs

- Aviation Safety (AVS) - 15 programs

- Airports (ARP) - 5 programs

- Aviation Policy, Planning and Environment (AEP) - 4 programs

- Commercial Space Transportation (AST) - 1 program

Activities described in the NARP include applied research as well as development. Applied research is characterized in the Office of Management and Budget Circular A-11 [5] as systematic study to gain knowledge or understanding needed to determine how recognized and specific needs may be met. The circular characterizes development as the systematic application of knowledge or understanding directed toward the production of useful materials, devices, and systems or methods, including design, development, and improvement of prototypes and new processes to meet specific requirements.

Table 2 shows the spread of efforts undertaken by the LOBs and classified either as applied research or as development. The table reflects the emphasis of AVS-related programs to provide the research foundation for FAA guidelines, handbooks, advisory circulars, rules and regulations that help to ensure the safety and efficiency of aircraft operations. This body of research includes the search for human factors and human performance information that the agency can provide to the aviation industry for use in designing and operating aircraft and in training pilots and maintenance personnel. 
Table 1. Alignment of Aviation Goals

\begin{tabular}{|c|c|c|c|}
\hline $\begin{array}{l}\text { Flight Plan } \\
\text { Goals }\end{array}$ & FAA R\&D Goals & $\begin{array}{l}\text { JPDO Guiding Principles and } \\
\text { Key Capabilities }\end{array}$ & $\begin{array}{l}\text { JPDO Integrated } \\
\text { Plan Goals }\end{array}$ \\
\hline \multirow[t]{2}{*}{ Greater Capacity } & $\begin{array}{l}\text { Fast, flexible, and } \\
\text { efficient }\end{array}$ & $\begin{array}{l}\text { Aircraft trajectory-based operations } \\
\text { Broad-area precision navigation } \\
\text { Equivalent visual operations } \\
\text { Performance-based services } \\
\text { Super-density operations } \\
\text { Weather assimilated into decision-making }\end{array}$ & Expand Capacity \\
\hline & Clean and quiet & Integrated environmental performance & $\begin{array}{l}\text { Protect the } \\
\text { Environment }\end{array}$ \\
\hline Increased Safety & $\begin{array}{l}\text { Human-centered design } \\
\text { Human protection } \\
\text { Safe aerospace vehicle } \\
\text { Self separation } \\
\text { Situational awareness } \\
\text { System knowledge }\end{array}$ & Proactive safety risk management & Ensure Safety \\
\hline $\begin{array}{l}\text { International } \\
\text { Leadership }\end{array}$ & World leadership & Global harmonization & $\begin{array}{l}\text { Retain U.S. } \\
\text { Leadership in Global } \\
\text { Aviation }\end{array}$ \\
\hline $\begin{array}{l}\text { Organizational } \\
\text { Excellence }\end{array}$ & $\begin{array}{l}\text { High quality teams and } \\
\text { individuals }\end{array}$ & User focused & \\
\hline Not Applicable & Not Applicable & $\begin{array}{l}\text { Layered adaptive security } \\
\text { Net-enabled information access }\end{array}$ & $\begin{array}{l}\text { Secure the Nation } \\
\text { Ensure our National } \\
\text { Defense }\end{array}$ \\
\hline
\end{tabular}

Table 2. R\&D Efforts by LOBs

\begin{tabular}{|c|c|c|c|}
\hline LOB & Research & Development & Total \\
\hline ATO & 6 & 13 & 19 \\
\hline AVS & 14 & 1 & 15 \\
\hline ARP & 3 & 2 & 5 \\
\hline AEP & 2 & 2 & 4 \\
\hline AST & 1 & 0 & 1 \\
\hline Total & 26 & 18 & 44 \\
\hline
\end{tabular}

FAA draws upon research sponsored by AVS when issuing aircraft fire safety rules that govern material selection, design criteria, and operational procedures - including guidance, new materials and government-owned patents that support regulatory compliance.

The contrasting developmental emphasis shown in programs supporting ATO reflects requirements to assess the interaction of changing roles and responsibilities of National Airspace System (NAS) service providers and pilots, airspace changes, procedural changes and new automation systems for distributing traffic, weather, and other flight-related information. ATO involvement drives $30.8 \%$ of the R\&D efforts of the MITRE Center for Advanced Aviation Systems Development (CAASD) in FY 2008 and will drive $37.8 \%$ in FY 2009 and beyond. CAASD's R\&D efforts span identifying and testing new concepts and technologies for the NAS in the areas of aviation safety, performance-based navigation, airspace design, and traffic flow management, and they include developing sophisticated models and prototypes to test concepts and systems proposed for use in the management and control of air traffic.

The alignment of FAA LOBs with R\&D Goals, shown in Table 3, reflects how some programs support multiple R\&D Goals.

Accordingly, each instance of LOB involvement may be classified either as full contribution or in coordination with others. 
Table 3. R\&D Programs Used By Lines of Business to Address R\&D Goals

\begin{tabular}{|l|c|c|c|c|c|}
\hline $\begin{array}{l}\text { Lines of Business } \\
\text { R\&D Goals }\end{array}$ & AEP & ARP & AST & ATO & AVS \\
\hline 2.1 Fast, flexible, and efficient & & 2 & & 6 & 1 \\
\hline 2.2 Clean and quiet & 3 & 1 & & 2 & \\
\hline 2.3 High quality teams and individuals & & & & 4 & \\
\hline 2.4 Human-centered design & & & & 5 & 4 \\
\hline 2.5 Human protection & & 2 & 1 & & 5 \\
\hline 2.6 Safe aerospace vehicles & & & 1 & 1 & 7 \\
\hline 2.7 Self-separation & & & & 3 & 2 \\
\hline 2.8 Situational awareness & & 2 & & 7 & 4 \\
\hline 2.9 System knowledge & 1 & & & 7 & 5 \\
\hline 2.10 World leadership & 1 & & & 4 & 29 \\
\hline Total & 5 & 7 & 2 & 39 & \\
\hline
\end{tabular}

\section{Key Milestones and Activities}

For each R\&D goal, the 2008 NARP identifies one key mid-term milestone in 2015 to 2016 that best defines its research contribution to FAA and NextGen goals. Each milestone is incrementally addressed through time-phased activities and outputs required to achieve it.

Table 4 shows how R\&D programs contribute to multiple FAA Performance Goals of Safety, Reduce Congestion, and Environment. Some programs contribute to multiple Performance Goals and are counted in each instance of full contribution or coordination.
The NARP identifies budget levels needed to accomplish each R\&D goal. Because some activities rely on support from more than one $R \& D$ program, however, researchers know they must collaborate across efforts, and managers know they must integrate their limited research budgets. The NARP explains how the R\&D milestones will be validated through means such as modeling, key demonstrations, prototypes, field trials, full-scale tests, and software beta tests. The 2008 NARP describes how the $R \& D$ programs are progressing toward achieving overall R\&D milestones and other planning targets.

Table 4. R\&D Programs Supporting Performance Goals to R\&D Goals

\begin{tabular}{|l|c|l|c|c|}
\hline $\begin{array}{l}\text { Performance Goals } \\
\text { R\&D Goals }\end{array}$ & Safety & $\begin{array}{l}\text { Reduce } \\
\text { Congestion }\end{array}$ & Environment & Total \\
\hline 2.1 Fast, flexible, and efficient & 1 & 8 & & 9 \\
\hline 2.2 Clean and quiet & & 2 & 4 & 6 \\
\hline 2.3 High quality teams and individuals & 1 & 3 & & 4 \\
\hline 2.4 Human-centered design & 3 & 7 & 1 & 11 \\
\hline 2.5 Human protection & 8 & & & 8 \\
\hline 2.6 Safe aerospace vehicles & 8 & 1 & & 9 \\
\hline 2.7 Self-separation & 1 & 3 & & 4 \\
\hline 2.8 Situational awareness & 6 & 5 & & 11 \\
\hline 2.9 System knowledge & 3 & 8 & 1 & 12 \\
\hline 2.10 World leadership & 5 & 5 & 2 & 12 \\
\hline Total & 36 & 42 & 8 & 86 \\
\hline
\end{tabular}


Across the ten R\&D goals and their milestones the NARP identified 160 research activities, including 76 activities (47.5\%) funded through NextGen R\&D programs. The relationship of these activities to their respective $R \& D$ goals is shown in Table 5. An activity is considered a NextGen component if at least one NextGen R\&D program contributes to it. There are limited numbers of activities that have been mapped to more than one $\mathrm{R} \& \mathrm{D}$ goal, but each is counted only once.
Table 6 designed to illustrate the time phasing of these activities, shows that in 2008 there are 16 activities being tracked as contributing to the $R \& D$ goals. Of these, eight activities demonstrate the important technical contribution of $R \& D$ to NextGen development.

Table 5. Composition of R\&D Activities

\begin{tabular}{|l|c|c|c|}
\hline R\&D Goal & All Activities & $\begin{array}{l}\text { NextGen } \\
\text { Activities }\end{array}$ & $\begin{array}{l}\text { \% } \\
\text { NextGen }\end{array}$ \\
\hline 2.1 Fast, flexible, and efficient & 20 & 8 & $40 \%$ \\
\hline 2.2 Clean and quiet & 23 & 13 & $57 \%$ \\
\hline 2.3 High quality teams and individuals & 13 & 9 & $69 \%$ \\
\hline 2.4 Human-centered design & 10 & 8 & $80 \%$ \\
\hline 2.5 Human protection & 11 & 0 & 0 \\
\hline 2.6 Safe aerospace vehicles & 15 & 0 & 0 \\
\hline 2.7 Self-separation & 20 & 20 & $100 \%$ \\
\hline 2.8 Situational awareness & 20 & 5 & $25 \%$ \\
\hline 2.9 System knowledge & 21 & 12 & $57 \%$ \\
\hline 2.10 World leadership & 7 & 1 & $14 \%$ \\
\hline Total & 160 & 76 & $47.5 \%$ \\
\hline
\end{tabular}

Table 6. Activity Timeline

\begin{tabular}{|l|c|c|c|}
\hline Year & $\begin{array}{l}\text { All } \\
\text { Activities }\end{array}$ & $\begin{array}{l}\text { NextGen } \\
\text { Activities }\end{array}$ & $\begin{array}{l}\text { \% } \\
\text { NextGen }\end{array}$ \\
\hline 2008 & 16 & 4 & $25 \%$ \\
\hline 2009 & 5 & 2 & $40 \%$ \\
\hline 2010 & 29 & 13 & $45 \%$ \\
\hline 2011 & 27 & 13 & $48 \%$ \\
\hline 2012 & 38 & 8 & $21 \%$ \\
\hline 2013 & 20 & 15 & $75 \%$ \\
\hline 2014 & 7 & 7 & $100 \%$ \\
\hline 2015 & 12 & 9 & $75 \%$ \\
\hline 2016 & 6 & 5 & $83 \%$ \\
\hline Total & 160 & 76 & $47.5 \%$ \\
\hline
\end{tabular}

Program requirements presented in the $J P D O$ $R \& D$ Plan [6] are organized into 12 categories that are similar to the domains and solution sets associated with the NextGen Implementation Plan and the earlier OEP. These JPDO categories are comprised of $R \& D$ requirements that are further associated with specific R\&D needs.

Table 7 shows the mapping of the $R \& D$ programs addressed by FAA NextGen R\&D programs in coordination with FAA sponsors to any of $60 \mathrm{R} \& \mathrm{D}$ requirements listed in the JPDO R\&D Plan. These 60 needs range in detail from specific research problems to higher level issues. The FAA R\&D programs that help to address these 60 needs pertain to Aviation Safety (AVS), Air Traffic Organization (ATO), and (through a unique mapping involving only 15 of the full set of needs) Environment and Energy (AEP). Of the remaining 45 needs in the JPDO R\&D Plan, 28 needs are addressed by AVS and ATO program components working in combination. To round out this picture, small numbers of R\&D needs are addressed by programs uniquely supporting either the AVS or the ATO LOB. 
Table 7. Map of NextGen Programs to JPDO R\&D Plan

AA NextGen R\&D program addresses JPDO research needs Management applied across all applicable NextGen research need IIIIII No funding applied - coordination only

Work performed by core activity

\begin{tabular}{|c|c|c|c|c|c|c|c|c|c|c|c|c|c|c|c|}
\hline \multirow{2}{*}{\multicolumn{3}{|c|}{$\begin{array}{l}\text { Key: } \\
\text { FAA NextGen R\&D program addresses JPDO research needs } \\
\text { Management applied across all applicable NextGen research needs } \\
\text { Wo funding applied - coordination only } \\
\text { Work performed by core activity }\end{array}$}} & \multicolumn{13}{|c|}{ FAA NextGen R\&D Programs } \\
\hline & & & 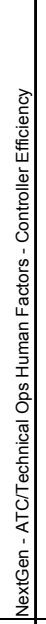 & 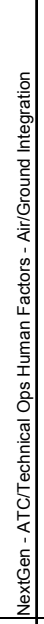 & 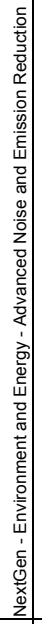 & 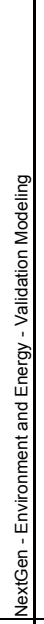 & 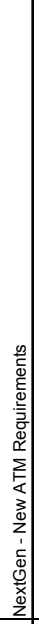 & 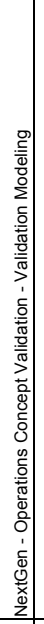 & 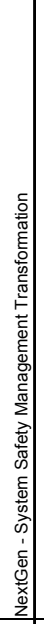 & 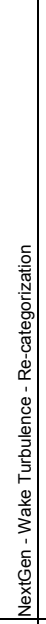 & 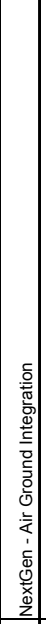 & 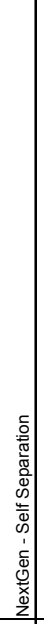 & 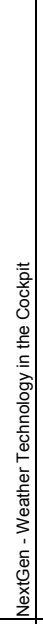 & 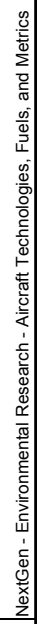 & 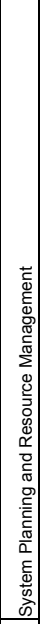 \\
\hline $\begin{array}{c}\text { JPDO } \\
\text { R\&D Requirements }\end{array}$ & & $\begin{array}{c}\text { JPDO R\&D Plan } \\
\text { Needs }\end{array}$ & 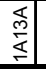 & 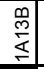 & 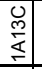 & 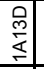 & $\underset{⿱ 亠 䒑}{\frac{m}{5}}$ & 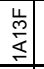 & 足 & \begin{tabular}{|c|} 
\\
\\
\\
\end{tabular} & $\begin{array}{c}\dot{\dot{j}} \\
\stackrel{\mathrm{i}}{<} \\
\end{array}$ & $\stackrel{\dot{i}}{\stackrel{i}{i}}$ & 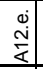 & $\stackrel{\frac{\rho}{m}}{\frac{m}{<}}$ & 㲾 \\
\hline \multirow{3}{*}{ Trajectory-Based Operations } & 1 & Performance-based Separation & & & & & & & & & & & & & \\
\hline & 2 & $\begin{array}{l}\text { Management of Complexity and Demand } \\
\text { Volume }\end{array}$ & & & & & & & & & & & & & \\
\hline & 3 & Airspace Configuration & & & & & & & & & & & & & \\
\hline \multirow{3}{*}{ Reduced Impact of Weather } & 1 & $\begin{array}{l}\text { Weather Information Integrated into Decision- } \\
\text { Making }\end{array}$ & & & & & & & & & & & & & \\
\hline & 2 & Common Weather Situational Awareness & & & & & & & & & & & & & \\
\hline & 3 & Observation and Forecast Qualities & & & & & & & & & & & & & \\
\hline \multirow{3}{*}{$\begin{array}{l}\text { Flexible Terminal Airspace and } \\
\text { Expanded Airport Access }\end{array}$} & 1 & $\begin{array}{l}\text { Access to Terminal Airspace for Arrivals and } \\
\text { Departures }\end{array}$ & & & & & & & & & & & & & \\
\hline & 2 & $\begin{array}{l}\text { Maintain Terminal Airspace and Surface } \\
\text { Operations in Low Visibility }\end{array}$ & & & & & & & & & & & & & \\
\hline & 3 & Overly Conservative Wake Vortex Separations & & & & & & & & & & & & & \\
\hline \multirow{4}{*}{$\begin{array}{l}\text { High-Density Terminal and Airport } \\
\text { Operations }\end{array}$} & 1 & Maximizing Individual Runway Capacity & & & & & & & & & & & & & \\
\hline & 2 & Maximizing Multiple-Runway Capacity & & & & & & & & & & & & & \\
\hline & 3 & $\begin{array}{l}\text { Manage Ramp Operations, Surface Traffic, and } \\
\text { Runway Assignments }\end{array}$ & & & & & & & & & & & & & \\
\hline & 4 & $\begin{array}{l}\text { Manage High-Density Arrival and Departure } \\
\text { Flows }\end{array}$ & & & & & & & & & & & & & \\
\hline \multirow{3}{*}{ Collaborative Air Traffic Management } & 1 & Shared Situational Awareness & & & & & & & & & & & & & \\
\hline & 2 & $\begin{array}{l}\text { Collaboration and Enhanced Flight Plan } \\
\text { Negotiation }\end{array}$ & & & & & & & & & & & & & \\
\hline & 3 & Trajectory and Flow Management & & & & & & & & & & & & & \\
\hline \multirow[b]{2}{*}{ Safety } & 1 & Safer Systems are Needed & & & & & & & & & & & & & \\
\hline & 2 & $\begin{array}{l}\text { Identify Proactively Safety Risks and Safety } \\
\text { Assurance Process }\end{array}$ & & & & & & & & & & & & & \\
\hline \multicolumn{16}{|l|}{ Layered, Adaptive Security } \\
\hline Environment & 1 & Keeping air transportation clean and quiet & & & & & & & & & & & & & \\
\hline \multirow{4}{*}{ Transformed Facilities } & 1 & Air Traffic Management Facility Optimization & & & & & & & & & & & & & \\
\hline & 2 & \begin{tabular}{|l|} 
Expanded Tower Services and Increased Tower \\
Staff Productivity
\end{tabular} & & & & & & & & & & & & & \\
\hline & 3 & $\begin{array}{l}\text { Air Traffic Management Workforce Skills and } \\
\text { Training }\end{array}$ & 姍 & & & & & & & & & & & & \\
\hline & 4 & $\begin{array}{l}\text { National Communications, Navigation, } \\
\text { Surveillance, and Timing Infrastructure }\end{array}$ & & & & & & & & & & & & & \\
\hline \multirow{3}{*}{$\begin{array}{l}\text { Aircraft, Operator, and Air } \\
\text { Transportation User Requirements }\end{array}$} & 1 & $\begin{array}{l}\text { Tradeoffs for Aircraft-Related Investments and } \\
\text { Policies }\end{array}$ & & & & & & & & & & & & & \\
\hline & 2 & $\begin{array}{l}\text { Reduced Time to Introduce Airframe, Avionics, } \\
\text { and Procedure Changes }\end{array}$ & & & & & & & & & & & & & \\
\hline & 3 & Unmanned Aircraft System (UAS) Operations & & & & & & & & & & & & & \\
\hline \multicolumn{16}{|l|}{$\begin{array}{l}\text { Airport and Air Transportation } \\
\text { Infrastructure Development }\end{array}$} \\
\hline \multirow{2}{*}{$\begin{array}{l}\text { Cross-Cutting Research and } \\
\text { Development }\end{array}$} & 1 & Human Error Mitigation and Risk Management & & & & & & & & & & & & & \\
\hline & 2 & NextGen Mission Analysis & & & & & & & & & & & & & \\
\hline
\end{tabular}


Several R\&D programs have been crafted to address the challenges posed by NextGen starting in Fiscal Year 2009. This includes the NextGen Weather Technology in the Cockpit program will enable flight deck weather information technologies that will provide flight crews with timely, comprehensive weather information from on-board sensors, cross-link from nearby aircraft, and up-link from ground processors to support flight replanning and weather hazard avoidance in flight. Research will support development of standards and guidance necessary to obtain design approvals for weather decision support systems for use in the cockpit as well as define minimum pilot training requirements including by use of human factors simulations.

Another initiative is the NextGen System Safety Management Transformation program that will promote expansion of the U.S. capability to meet national and international safety goals and objectives with less oversight of individual carriers. By developing a comprehensive set of safety management principles and practices, the program will facilitate an evolution of present certification, testing, and inspection of individual system elements toward comprehensive approvals of operators' and manufacturers' safety management programs. A key element of this program is called Aviation Safety Information Analysis and Sharing (ASIAS) and research includes developing a baseline for enhancing ASIAS data/information protection and access policies as well as data infrastructure, equipment, tools, and processes.

NextGen includes important research on the environmental and energy challenges posed by increasing capacity threefold while reducing significant environmental impacts in absolute terms. Research investigates impacts of Continuous Low Energy, Emissions and Noise (CLEEN) technologies and alternative fuels. The FAA collaborates with NASA and Transport Canada through the Partnership for AiR Transportation Noise and Emissions Reduction (PARTNER) Center of Excellence in studying airport air quality to refine best practices. The program collaborates with industry in advancing engine and airframe technologies to reduce aviation noise, greenhouse gas emissions, and energy use. These efforts will ultimately support dynamic environmental management systems with goals and targets to better manage aviation's environmental impacts.

NextGen capabilities and operational concepts pose evolutionary changes in the roles between pilots and controllers and in the advanced automation they will use to ensure safe and efficient flights. NextGen human factors research will define technical information needed to support development of standards, procedures, and training by Flight Standards for improving surface and runway operations awareness, and delegating responsibility to the flight deck such as for reducing arrival and departure spacing. Researchers will develop and assess design concepts for en route, terminal and tower workstations for increasing the efficiency and effectiveness of the controller workforce. Research will improve the design of computer-human interfaces to reduce information overload and the potential for errors that might result from automation failure. This research is being integrated through leadership shared by AVS and ATO in developing a personnel roadmap for the enterprise architecture.

As these programs complete their research, the new concepts, technologies, and procedures will be transitioned to the NextGen Integration and Implementation office that will further mature those capabilities as part of the NextGen Implementation Plan. For more information on this Plan, you can download it at:

http://www.faa.gov/about/office_org/headquarters_ offices/ato/publications/nextgenplan/

\section{Portfolio Business Management}

The FAA R\&D portfolio includes 44 programs that support regulation, certification, and standards development; modernization of the national airspace system; and policy and planning. A primary distinction is made in the FAA R\&D portfolio regarding roles of sponsors and performers. Sponsors identify research needs, assign priorities to these needs, and evaluate outputs from research projects for supporting the needs. Performers plan, conduct and report on research projects. At the FAA, some sponsors have responsibility for performing their own research, whereas other sponsors have needs addressed by FAA research organizations in separate LOBs. 
The R\&D portfolio development process includes strategic planning, budget formulation, program execution, and program evaluation. The process improves the budgeting, selection, and management of programs; increases the return on taxpayer investment; enhances productivity; and ensures the relevance, quality, and performance of the overall $R \& D$ program.

Strategic planning for the $R \& D$ portfolio is provided by the NARP, which links FAA's R\&D activities to the broader strategic planning of the FAA Flight Plan, NextGen Implementation Plan, and the JPDO. The R\&D Executive Board (REB) uses strategic planning guidance to formulate the agency's R\&D portfolio. This portfolio includes programs funded from four appropriation accounts: Research, Engineering and Development (R,E\&D); Air Traffic Organization (ATO) Capital; Airport Improvement Program (AIP); and Safety and Operations (S\&O). The REB determines how any new monies should be spent and analyzes any gaps that must be considered in its dynamic decisionmaking process. The REB also coordinates the various iterations of the portfolio with upper-level management within the FAA - including the NextGen Review Board, ATO Executive Council, and Joint Resources Council. This well-established process ensures both top-down and bottom-up coordination for a well-balanced portfolio.

The program managers are responsible for executing their respective portions of the portfolio. This includes working closely with the sponsors to ensure $R \& D$ results meet customer needs. Program managers possess scientific, engineering, and technical expertise and understand fair and open competition, performance management, and financial management. They use program funding developed in the formulation process, and approved by Congress, to award competitive grants, cooperative agreements and contracts, and to produce program accomplishments and results that achieve the strategic plan.

Various evaluation processes determine whether the accomplishments and results produced by the program meet the strategic plan, and whether the strategic plan is leading the $R \& D$ program in the right direction. The internal evaluation uses a database that captures the status of goals from the program White Sheets and allows program managers to track successes and highlight issues (funding, priority, or other). NextGen programs undergo internal evaluation through NextGen Service Level Agreements (NSLAs) that specify planned funding with scheduled milestones and measure annual progress against the plan. The R,E\&D Advisory Committee and its associated subcommittees conduct the external reviews of the program twice a year. These evaluations provide feedback into strategic planning and help ensure the relevance, quality, and performance of the R\&D portfolio.

The FY 2010 R\&D Portfolio Development Process Guidance Reference Document establishes the latest process for producing an $\mathrm{R} \& \mathrm{D}$ program that demonstrates a high level of relevance, quality, and performance [7]. Each year, this document:

(1) provides guidance to participants on the FAA $\mathrm{R} \& \mathrm{D}$ portfolio development process and to document the process; (2) minimizes the time required to understand and use the process and maximize the time available to manage programs and produce results; and (3) explains how the portfolio development process connects to the strategic planning, budget formulation, program execution, and evaluation of R\&D.

\section{R\&D Partnerships}

The FAA partners with government, industry, and academia to leverage critical national capabilities and to help ensure the FAA attains its R\&D goals. The FAA also uses cooperative agreements with European and North American aviation organizations to participate in air traffic management modernization programs and to leverage research activities that harmonize operations and promote a seamless air transportation system worldwide. The NARP explains the FAA partnership activities and identifies all active agreements with other government agencies, cooperative $\mathrm{R} \& \mathrm{D}$ agreements, patents, and grants.

\section{Discussion}

R\&D will help FAA achieve NextGen objectives by identifying challenges, understanding barriers, and developing solutions associated with capacity, safety, environment, controller efficiency, 
and pilot workload. The agency's ten R\&D milestones are aggressive and challenge researchers to innovate, take risks, and seek non-traditional solutions. Some results will succeed beyond expectations, while others may fall short of the intended target. Research will make the unknown, known. It will identify constraints and barriers, separate solutions that are effective from those that are not, and help transform the nation's air transportation system by the year 2025 .

\section{References}

[1] Federal Aviation Administration, 2008, National Aviation Research Plan, Washington, DC, http://nasarchitecture.faa.gov/nas/downloads/home.cfm or http://research.faa.gov

[2] Federal Aviation Administration, 2008, NextGen Implementation Plan, Washington, DC, http://www.faa.gov/about/office_org/headquarters offices/ato/publications/nextgenplan/

[3] Federal Aviation Administration, September 2007, 2008-2012 Flight Plan, http://www.faa.gov/about/plans_reports/media/FPP _Flight Plan 2008-2012.pdf

[4] Joint Planning and Development Office, December 2004, Next Generation Air Transportation System Integrated Plan,
Washington, DC, http://www.jpdo.gov/library/NGATS_v1_1204r.pdf

[5] OMB Circular A-11, Preparation, Submission and Execution of the Budget, June 2006, section 84, page 8 , http://whitehouse.gov/OMB/circulars

[6] Joint Planning and Development Office, August 31, 2007, Next Generation Air Transportation System R\&D Plan, Washington, DC.

[7] Federal Aviation Administration, 2008, FY 2010 $R \& D$ Portfolio Development Process Guidance Reference Document, Washington, DC, http://nasarchitecture.faa.gov/nas/downloads

\section{Disclaimer}

The views expressed are those of the authors and do not represent the Federal Aviation Administration.

\section{Email Addresses}

Paul Krois: Paul.Krois@,faa.gov

Lee Olson: Lee.Olson@faa.gov

Cathy Bigelow: Cathy.Bigelow@faa.gov

27th Digital Avionics Systems Conference

October 26-30, 2008 